\title{
HISTÓRIA E ORIGEM EM WALTER BENJAMIN
}

Pedro Alcântara

\section{RESUMO}

A singularidade da produção literária e filosófica de Walter Benjamin é marcada, dentre outras coisas, pela valorização da alegoria, da compreensão do rompimento do fluxo e do enaltecimento dos fragmentos, tanto na história como na escrita. $O$ presente artigo tem como objetivo estabelecer uma relação entre os principais elementos que constituem o conceito de história e o significado do conceito de origem (URSPRUNG), tendo como fundamento de análise as obras Origem do Trauerspiel Alemão e as teses Sobre o conceito de História.

Palavras-chave: História. Origem. Benjamin. Tragédia. Linguagem.

\section{HISTORY AND ORIGIN IN WALTER BENJAMIN}

\begin{abstract}
The uniqueness of Walter Benjamin's literary and philosophical production is marked, among other things, by the valorization of allegory, by the understanding of the bursting of the flow and the enhancement of fragments, both in history and in writing. The present article aims to establish a relationship between the main elements that constitute the concept of history and the meaning of the concept of origin (URSPRUNG), based on the work Origins of the German Trauerspiel and the theses On the concept of History.
\end{abstract}

Key-words: History. Origin. Benjamin. Tragedy. Language. 
"O passado traz consigo um índice secreto, que o impele à redenção."

BENJAMIN

A integralidade e o dinamismo ao qual o pensamento e a produção textual de Walter Benjamin se entrelaçam, é sem dúvida uma marca da singularidade do intelectual, filósofo e crítico literário alemão. O caráter único que pode ser apreendido no seu modo alegórico, poético e fragmentado de escrita é relativo à sua própria compreensão e conceituação da história. Rompimento do fluxo dos fenômenos históricos, recolhimento dos fragmentos que outrora se encontravam à margem da investigação tradicional, é o modo pelo qual Benjamin traz à tona o significado e valor dos acontecimentos que foram desprezados e esquecidos. Por esse fato é que em Benjamin não há espaço para esquematizações e métodos delimitados. "Não há, em Benjamin, um sistema filosófico: toda a sua reflexão toma a forma do ensaio ou fragmento - quando não se trata da citação pura e simples, com passagens retiradas de contexto e colocadas a serviço de sua própria dinâmica" (LÖWY, 2002, 199). Constatação esta que pode ser percebida nas duas principais referências ao qual este ensaio propôs analisar, qual seja, Origem do Trauerspiel Alemão, de 1928 e as conhecidas teses Sobre o Conceito de História, de 1940. Walter Benjamin é parte de um espírito de época alemão ao qual há uma ascensão de jovens judeus, já estabelecidos economicamente, que ingressam no estudo acadêmico. Desse modo, os referenciais teóricos do jovem Benjamim, e que iriam se consolidar em sua vida e obra, são múltiplas, a saber, o romantismo alemão, o messianismo judaico e o marxismo. Como destaca Michael Löwy

A filosofia da história de Walter Benjamin bebe em três fontes: 0 romantismo alemão, o messianismo judeu e o marxismo. Não é uma combinatória ou "síntese" dessas três perspectivas (aparentemente) incompatíveis, mas a invenção, a partir delas, de uma nova concepção, profundamente original (LÖWY, 2002, 199).

A crítica à civilização burguesa, ao progresso (e desigualdade) econômico e ao florescimento do tecnicismo foi tema característico do utopismo romântico 
presente na Europa Central a partir dos meados do século XIX, e início do século $X X^{1}$, que defendia os valores éticos, culturais, estéticos e religiosos do período antecessor ao capitalismo. Consoante a isso há a ascensão de uma cultura judaico-alemã que tem como referência o misticismo da religião judaica e seus conceitos de restauração da ordem e messianismo redentivo. Benjamin é parte do grupo de intelectuais que receberam influência desse sincretismo presente na Europa, e que também - sobretudo Benjamin- no marxismo, fundamentariam seus referencias teóricos. Há em Benjamin uma "afinidade eletiva" entre messianismo judaico e utopia libertária.

\begin{abstract}
Para o intelectual judeu que pertence à "geração romântica" dos anos 1880 , que participava às vezes dos círculos alemães informais onde era elaborada a cultura romântica anticapitalista - como o círculo de Max Weber de Heidelberg, frequentado por Lukács e Bloch -, um problema se apresentava de imediato: o retorno ao passado, que estava no núcleo da atitude romântica, nutria-se de referências nacionais (a germanidade ancestral), sociais (a aristocracia medieval), ou religiosas (a cristandade protestante ou católica) das quais ele, enquanto judeu, achava-se radicalmente excluído... Para outros, isto é, a maioria, não haviam senão duas saídas possíveis (no quadro neoromântico): um retorno às suas próprias raízes históricas, à sua própria cultura, nacionalidade ou religião ancestral, ou a adesão a uma utopia romântico-revolucionária de caráter universal. Não é de se admirar que um grande número de pensadores judeus de cultura alemã, próximos ao romantismo anti-capitalista, tenha escolhido simultaneamente os dois caminhos, sob a forma redescoberta da religião judaica - em particular da dimensão restauradora utópica do messianismo - e de sua simpatia ou indefinição com utopias revolucionárias (sobretudo literárias) profundamente carregadas do passado ( LÖWY, 1989, 3637).
\end{abstract}

Diante de tal apresentação contextual, nosso objetivo no presente ensaio é apresentar, de modo introdutório, conceitos elementares presentes no prefácio de Origem do Drama Barroco Alemão (Ursprung des deutschen Trauerspiels) de 1928 dialogando, por fim com as teses Sobre o Conceito de História, último escrito de Benjamin, publicadas após sua morte, em 1940, demonstrando que

\footnotetext{
1 Essa é a tese de Michael Löwy, apesar de sem uma interpretação singular do autor e de ter recebido várias críticas, optamos por tomar seu pensamento como ponto de partida para o desenvolvimento do trabalho. Outra importante interpretação, e que traz uma abordagem distinta à essa, é da Professora Jeanne Marie Gagnebin, em sua obra Walter Benjamin- Os cacos da história.
}

Mestre em Filosofia pela UFG. Brasileiro, Residente em Goiânia-GO. E-mail: pedroibef@gmail.com 
há- diferentemente do pensamento de que Benjamin possui "fases" e cortes epistemológicos ${ }^{2}$ - uma continuidade de certos temas já presentes em sua juventude, que serão essenciais para a sua produção tardia.

\title{
1 Origem do Trauerspiel Alemão, conceitos do prólogo.
}

A amplitude da obra Origem do Trauerspiel Alemão é de caráter multidisciplinar. Muito mais do que apenas uma investigação aprofundada das obras literárias e dramatúrgicas do drama barroco alemão do século XVII, a célebre obra benjaminiana dialoga com história, política, estética e linguagem. 0 propósito de Benjamin com a sua investigação sobre o drama alemão é propor uma nova leitura para este movimento literário e artístico. Benjamin chama a atenção para um erro presente em seu tempo, cometido por alguns críticos literários, em não diferenciar os termos "Trauerspiel" e "tragédia" grega.

\begin{abstract}
Sem se interrogarem sobre as causas profundas que determinaram tais variações, os comentadores concluíram, rápida e levianamente, que se tratava de uma incompreensão que levou a distorções; e foi apenas um passo daí até à afirmação de que os dramaturgos da época mais não tinham feito do que aplicar, sem os compreender, uns quantos preceitos respeitáveis de Aristóteles. O drama trágico do Barroco alemão passou a ser visto como uma caricatura da tragédia antiga (BENJAMIN, 2013, 39).
\end{abstract}

Assim, o filósofo introduz ao campo científico e estético uma nova terminologia, ao qual, traz uma diferenciação do conceito de tragédia (Tragödie) e drama trágico (Trauerspiel) ${ }^{3}$. Os dramas do Barroco expressam desespero e

\footnotetext{
2 Sobre o perigo de tal interpretação, Löwy destaca: "Na literatura sobre Benjamin deparamonos, frequentemente, com dois erros simétricos, que devem ser evitados a todo custo: o primeiro consiste em dissociar, por meio de uma operação (no sentido clínico do termo) de "corte epistemológico", a obra de juventude "idealista" e teológica da "materialista" e revolucionária da maturidade; o segundo, em contrapartida, encara sua obra como um todo homogêneo e não leva absolutamente em consideração a alteração profunda trazida, por volta dos anos 20, pela descoberta do marxismo. Para compreender o movimento do seu pensamento, é preciso, pois, considerar simultaneamente a continuidade de certos temas essenciais e as diversas curvas e rupturas que pontilham sua trajetória intelectual e política" (LÖWY, 2002, 199).

3 Literalmente, Trauerspiel pode ser traduzido por "drama lutuoso".
} 
desprezo do mundo - são peças tristes, carregadas de teor melancólico; já a atitude dos tragediógrafos gregos e dos poetas propriamente trágicos em relação ao mundo e ao destino é a de uma total inflexibilidade. Na dramaturgia barroca há tristeza, luto e apatia. Na tragédia grega há mito, catarse, empatia. Nos escritos intitulados Drama Barroco e Tragédia e $O$ significado da linguagem no Drama Barroco e na Tragédia, Benjamin apresenta uma dupla diferenciação entre drama trágico e tragédia, diferença histórica e linguística. No aspecto histórico há a distinção entre o tempo da história e o tempo mecânico. O tempo da história é infinito e não pode ser preenchido em cada um dos seus momentos. Nenhum evento é capaz de preenchê-lo na sua totalidade. A tragédia se caracteriza por assumir esse aspecto histórico. Diferente do tempo messiânico, que é a ideia do tempo preenchido, ocasionado por uma indeterminação empírica, divina.

É em seu posicionamento diverso frente ao tempo histórico que se distinguem o drama barroco e a tragédia. Na tragédia, o herói morre, visto que ninguém é capaz de viver no tempo preenchido. Ele morre de imortalidade. A morte é uma imortalidade irônica; esta é a origem da ironia trágica. A origem da culpa trágica situa-se na mesma área. Ela repousa no tempo próprio do herói trágico, preenchido de modo puramente individual (BENJAMIN, 2013, 60).

A morte, no drama barroco, não está fundamentada num determinismo ao qual o tempo individual confere ao evento. Não é o ponto final, é passagem, repetição, Spie/4 (jogo).

\begin{abstract}
É na repetição que repousa a lei do drama barroco. Seus eventos são sombras metafóricas, reflexos simbólicos de outro jogo. A morte arrebata para dentro desse jogo. O tempo do drama barroco é não preenchido e, não obstante, finito. Ele é não individual, sem que tenha generalidade histórica. O drama barroco, em qualquer sentido, é uma forma intermediária... O drama barroco esgota em termos artísticos a ideia histórica da repetição; por conseguinte, ele aborda um problema bem diferente da tragédia (BENJAMIN, 2013, 62).
\end{abstract}

Além de distinções enquanto aspecto histórico, o drama trágico e a tragédia carregam diferenciações no aspecto linguístico. A tragédia grega tem

\footnotetext{
4 Justamente, por isso que traduzir por "drama lutuoso", - não existe esta adjetivação na palavra original -, é ser parcial, pois se perde o lúdico - o Spiel, que é também drama/peça e relação ao verbo tocar (um instrumento), como "play" em inglês.

Mestre em Filosofia pela UFG. Brasileiro, Residente em Goiânia-GO. E-mail:
} 
por característica singular o discurso oral. "O trágico tem como base a legalidade do discurso oral entre os seres humanos. Não existe pantomima trágica. Tampouco existe poesia trágica, nem romance trágico, nem acontecimento trágico" (BENJAMIN, 2013, 64). Tragédia e interlocução inter-humana são vias de mão dupla. "Na tragédia, a palavra e a tragicidade se originam, simultaneamente, do mesmo lugar. Na tragédia, cada discurso é tragicamente decisivo. A pura palavra é imediatamente trágica" (BENJAMIN, 2013, 65). Já no drama barroco, a palavra não possui um caráter de significação pura. Esta possui o aspecto de transformação, ciclo. Desse modo, para Benjamin o drama barroco não tem como sustentáculo a linguagem real. "Onde na tragédia se ergue a petrificação eterna da palavra falada, o drama barroco concentra a ressonância sem fim de sua sonoridade" (BENJAMIN, 2013, 67).

Tratado de modo introdutório sobre a diferença entre drama trágico e tragédia, faz-se necessário conceituar o significado de Origem “Ursprung”, uma vez que a definição do conceito é elementar e presente na produção filosófica de Benjamin não apenas na obra sobre o drama barroco, mas também em vários outros tratados do filósofo. A princípio é necessário ressaltar que Benjamin opõe radicalmente o significado de origem à gênese. No prefácio da obra sobre o drama barroco Benjamin aponta o significado do termo origem:

\begin{abstract}
Apesar de ser uma categoria plenamente histórica, a origem (Ursprung) não tem nada em comum com a gênese (Entstehung). "Origem" não designa o processo de devir de algo que nasceu, mas antes aquilo que emerge do processo de devir e desaparecer. A origem insere-se no fluxo do devir como um redemoinho que arrasta no seu movimento o material produzido no processo de gênese. $O$ que é próprio da origem nunca se dá a ver no plano do factual, cru e manifesto. O seu ritmo só se revela a um ponto de vista duplo, que o reconhece, por um lado como restauração e reconstituição, e por outro como algo de incompleto e inacabado... A origem, portanto, não se destaca dos dados factuais, mas tem a ver com a sua pré e póshistória. Na dialética inerente à origem encontra a observação filosófica o registro das suas linhas-mestras (BENJAMIN, 2013, 34).
\end{abstract}

Origem, portanto, significa a transposição para fora do processo cronológico presente nas teorias da história tradicionais. Origem é a irrupção da linha do tempo, operando recortes no percurso da historiografia. Em consonância com o significado de origem, na perspectiva histórica de pré e pós- 
história, Benjamin introduz o conceito leibniziano de mônada enquanto "estrutura marcada pela totalidade, em contraste com o seu inalienável isolamento... A ideia é uma mônada. $O$ ser que nela penetra com a sua pré e pós história mostra, oculta na sua própria, a figura abreviada e ensombrada do restante do mundo das ideias" (BENJAMIN, 2013, 36). Ter o objeto como o ponto de partida de referência, tendo este em si mesmo o todo é o propósito da conceptualização de origem, como apresenta Jeanne Marie Gagnebin: "trata-se sempre da mesma ideia de totalização a partir do próprio objeto e nele, da referência a uma pré e pós-história irredutíveis ao desenvolvimento cronológico da Entstehung, que ele Ihe seja anterior ou posterior" (GAGNEBIN, 2013, 11).

Ao contrário da proposta platônica de atemporalidade, a origem é uma categoria que só pode ser desenvolvida na história. A origem presente em cada acontecimento histórico carrega dentro de si a potencialidade de salvar tais fenômenos. A figura ao qual Benjamin apresenta como simbolismo para tal processo redentivo é a constelação. No prefácio de sua obra ele ressalta: "As ideias são constelações eternas, e se os elementos se podem conceber como pontos em tais constelações, os fenômenos estão nelas simultaneamente dispersos e salvos" (BENJAMIN, 2013, 23).

Percorrido pelos trilhos conceituais presentes no prefácio da obra Origens do Trauerspiel Alemão, como o significado de drama trágico, tragédia, origem, constelação e redenção, faz-se necessário apresentar a presença de tais imagens na teoria da história de Walter Benjamin, presente nas suas famosas Teses Sobre o Conceito de História, com o objetivo de ressaltar a importância de alguns símbolos desenvolvidos pelo filósofo da sua obra sobre o drama barroco e a relação que estas possuem com a sua obra última, ambas apresentando um caráter temático multidisciplinar, estético, histórico, filosófico e político.

\section{Origem do Trauerspiel Alemão e Sobre o Conceito da História}

A confluência de perspectivas que constituíram o referencial teórico de Walter Benjamin apresentada na introdução deste ensaio, a saber, a utopia 
romântica, a teologia judaica e o marxismo estão presentes na construção não apenas nas obras sobre estética e política, mas também em suas teses sobre 0 conceito de história. Benjamin possui um entendimento da história como uma construção anti-linear, marcada por rupturas e descontinuidades, e não por como um progresso histórico como propôs Hegel. Para Benjamin, as propostas historicistas tradicionais que analisam os fatos do passado na tentativa de revivêlos de acordo com seus critérios próprios corroboram para a perpetuação da "história dos vencedores". Desse modo, Benjamin propõe desarticular a história dos vencedores através da explosão do continuum. $\mathrm{O}$ historiador deve pinçar um momento do continuum, transformando-o em objeto de análise, dando vida àquilo que outrora passou despercebido. Nesse sentido o conceito de origem se faz presente na teoria da história benjaminiana, pois é pela significação desta que se dá vida ao inaudito. É a partir de tal compreensão que Benjamin estabelece uma relação entre estética, obras arte e história. Assim também o caráter teológico judaico presente no pensamento de Benjamin se revela quando cabe ao historiador redimir, restaurar os fenômenos da história. O historiador deve mergulhar nos fragmentos a fim de apresentá-los de modo transcendente. O processo de restauração dos fenômenos históricos se dá através da rememoração (Eingedenken), medium de reflexão, por meio dos signos e documentos históricos. A categoria da rememoração está, sem dúvida, ligada à tradição teológica judaica.

\begin{abstract}
Contra essa visão linear e quantitativa, Benjamin opõe uma percepção qualitativa da temporalidade, fundada, de um lado, na rememoração, de outro na ruptura messiânica/revolucionária da continuidade. A revolução é o "correspondente 'no sentido baudelairiano da palavra' profano da interrupção messiânica da historia, da parada messiânica do devir" 'Tese XVIl': as classes revolucionárias, escreve na Tese XV, estão conscientes, no momento da ação, de "romper o contínuo da história". A interrupção revolucionária é, portanto, a resposta de Benjamin às ameaças que faz pesar sobre a espécie humana a perseguição da tempestade maléfica chamada "Progresso", uma tempestade que acumula ruínas e prepara catástrofes novas 'Tese XII' (LÖWY, 2002, 205).
\end{abstract}

Gagnebin nos esclarece a ligação entre a origem e o seu caráter de restauração: "A origem benjaminiana visa, portanto, mais que um projeto restaurativo ingênuo, ela é, sim, uma retomada do passado, mas ao mesmo tempo - e porque o passado enquanto passado só pode voltar numa não Mestre em Filosofia pela UFG. Brasileiro, Residente em Goiânia-GO. E-mail: 
identidade consigo mesmo - abertura sobre o futuro" (GAGNEBIN, 2013, 14). É certo que Benjamin traz um novo significado ao conceito de restauração diferente daquele puramente religioso advindo da tradição judaica. Sua significação possui um aspecto no plano histórico e não teológico, como destaca Márcio Seligmann-Silva: "Reconhecemos também o uso de 'teologemas', argumentos derivados do Antigo Testamento que são aplicados à esfera do profano" (SELIGMANN-SILVA, 2005, 25). Na Tese II, ao estabelecer uma relação entre a felicidade e as possibilidades perdidas no passado, Benjamin apresenta seu pensamento sobre o caráter redentor de sua teoria da história:

\begin{abstract}
A imagem da felicidade está indissoluvelmente ligada à da redenção. O mesmo ocorre com a representação do passado, que a história transforma em seu objeto. O passado traz consigo um índice secreto, que o impele à redenção. Pois não somos tocados por um sopro do ar que envolveu nossos antepassados? Não existem, nas vozes a que agora damos ouvidos, ecos de vozes que emudeceram? Não têm as mulheres que cortejamos irmãs que elas não chegaram a conhecer? Se assim é, então existe um encontro secreto marcado entre as gerações precedentes e a nossa. Então, alguém na terra esteve à nossa espera. Se assim é, foi-nos concedida, como a cada geração anterior à nossa, uma frágil força messiânica para a qual o passado dirige um apelo (BENJAMIN, 2012, 242).
\end{abstract}

O conceito de origem volta a ser tema de análise da Tese XIV, quando Benjamin cita a postura de Robespierre em retornar à Roma Antiga. Tal postura significa a ação da origem na unificação entre fenômenos históricos. Esse procedimento é denominado por Benjamin como (Jetzteit) 5 "tempo de agora" ao qual transcende do continuum da história. A unificação dos fenômenos históricos da Revolução Francesa e uma "Roma ressurreta" são oriundas da Ursprung. "Quando Robespierre cita a Roma antiga, Benjamin vê nesta retomada, talvez inábil, o esboço de uma ligação inédita entre dois fenômenos históricos; graças a esta ligação, dois elementos (ou mais) adquirem um novo sentido e desenham um novo objeto histórico" (GAGNEBIN, 2013, 15).

\footnotetext{
5 "A história é objeto de uma construção cujo lugar não é o tempo homogêneo e vazio, mas o preenchido de "tempo de agora" (jetztzeit). Assim, a Roma antiga era para Robespierre um passado carregado de "tempo de agora", que ele fez explodir para fora do continuum da história" (BENJAMIN, 2012, 249).
} 
Os elementos de confluência presentes no prefácio de Origens do Trauerspiel Alemão se fazem presentes de um modo abrangente na décima sétima tese Sobre o Conceito de História. Estão expressas ali as figuras de constelação, mônada, messianismo e explosão do continuum histórico. A caráter de verificação, permitam-me a longa citação de uma parte da Tese:

\begin{abstract}
O historicismo culmina legitimamente na história universal. Em seu método, a historiografia materialista distancia-se dela talvez mais radicalmente do que qualquer outra. A história universal não tem qualquer armação teórica. Seu procedimento é aditivo: ela utiliza a massa dos fatos, para com eles preencher o tempo homogêneo e vazio. A historiografia materialista, por outro lado, tem em sua base um princípio construtivo. Pensar não inclui apenas o movimento dos pensamentos, mas também sua imobilização. Quando o pensamento para, bruscamente, numa constelação saturada de tensões, ele the comunica um choque, através do qual ela se cristaliza numa mônada. O materialista histórico aproxima-se de um objeto histórico somente quando ele o confronta enquanto mônada. Nessa estrutura, ele reconhece o sinal de uma imobilização messiânica dos acontecimentos, ou, dito de outro modo, de uma oportunidade revolucionária na luta pelo passado oprimido. Ele aproveita essa oportunidade para explodir uma época determinada para fora do curso homogêneo da história; do mesmo modo, ele arranca à época uma vida determinada e, da obra composta durante essa vida, uma obra determinada (BENJAMIN, 2012, 251).
\end{abstract}

Na Tese XVII podemos encontrar a reunião de influências que Benjamin recebeu sendo concentradas numa formulação não menos brilhante de uma filosofia da história. O Benjamin de uma herança judaica, romântica e marxista, se apresenta de modo integral para dar voz aos "vencidos". Há aqui presente um projeto histórico revolucionário que reconhece que, apenas por meio da historiografia materialista, com seu aspecto construtivista, é que podemos ser capazes de trazer à luz elementos históricos que foram esquecidos pela historiografia tradicional. Benjamin propõe o conceito de um messianismo a serviço dos oprimidos, que só podem receber sua vitória, serem reconhecidos através do trabalho do historiador "colecionador de cacos" que traz vida ao passado a partir da transcendência dos objetos no fluxo contínuo da história.

\title{
REFERÊNCIAS
}

Mestre em Filosofia pela UFG. Brasileiro, Residente em Goiânia-GO. E-mail: pedroibef@gmail.com 
BENJAMIN, Walter. Magia e técnica, arte e política: ensaios sobre literatura e história da cultura. Trad. Sérgio Paulo Rouanet. 8 Ed. (Obras Escolhidas Vol.I). São Paulo: Brasiliense, 2012. . O Capitalismo como religião. Org. Michael Löwy. Trad. Nélio Schneider, Renato Pompeu. 1르 Ed. São Paulo: Boitempo, 2013. . Origem do Drama Trágico Alemão. Trad. João Barrento. $2^{\mathrm{a}} \mathrm{Ed}$. Belo Horizonte: Autêntica Editora, 20013.

GAGNEBIN, Jeanne Marie. História e Narração em Walter Benjamin. São Paulo: Perspectiva, 2013.

LÖWY, Michael. Redenção e Utopia: o judaísmo libertário na Europa central (um estudo de afinidade eletiva). Tradução Paulo Neves. São Paulo: Companhia das Letras, 1989.

. A Filosofia da História de Walter Benjamin. In__: Estudos Avançados. Vol 16. N.15. São Paulo, 2002.

SELIGMANN-SILVA, Márcio. Walter Benjamin: O Estado de Exceção entre o Político e o Estético. In_: Outra Travessia 5. Rio Grande do Sul, 2005. 